\title{
Hydraulic fracturing process by using a modified two-dimensional particle flow code - case study
}

\section{Luqing Zhang* and Jian Zhou}

Key Laboratory of Shale Gas and Geoengineering, Institute of Geology and Geophysics,

Chinese Academy of Sciences,

Beijing 100029, China

Email: zhangluqing@mail.iggcas.ac.cn

Email: zhoujian@mail.iggcas.ac.cn

*Corresponding author

\section{Zhenhua Han}

Key Laboratory of Shale Gas and Geoengineering, Institute of Geology and Geophysics,

Chinese Academy of Sciences,

Beijing 100029, China

and

College of Earth Science,

University of Chinese Academy of Sciences,

Beijing 100049, China

Email: hanzhenhua13@mails.ucas.ac.cn

\begin{abstract}
By using a modified $\mathrm{PFC}^{2 \mathrm{D}}$ model, the authors conducted a series of simulations to examine the influences of in-situ stress ratio, fluid injection rate, anisotropy of laminated rocks, and perforation parameters on hydraulic fracturing process. The simulations indicated that: 1) larger in-situ stress ratio will induce smaller breakdown pressures and faster propagation, and hydraulic fractures will extend along the direction of the maximum principal stress or approach to this preferred path; 2) smaller difference of in-situ stresses or faster fluid injection rate is helpful for creation of complex fracture network; 3) weak layers are preferred locations and directions for fracture initiation and propagation in the laminated rocks; 4) hydraulic fractures initiate easily at the bottoms of perforation channels, and propagate generally along or approaching to the direction of maximum principal stress.
\end{abstract}

Keywords: a modified $\mathrm{PFC}^{2 \mathrm{D}}$ model; isotropic medium; the laminated rock; in-situ stress ratio; fluid injection rate; dip angle of bedding planes.

Reference to this paper should be made as follows: Zhang, L., Zhou, J. and Han, Z. (2017) 'Hydraulic fracturing process by using a modified two-dimensional particle flow code - case study', Progress in Computational Fluid Dynamics, Vol. 17, No. 1, pp.13-26.

Biographical notes: Luqing Zhang is an Associate Professor in the Institute of Geology and Geophysics, Chinese Academy of Sciences. His research interests involve rock mechanics and geological engineering. He received his Master degree in Rock Mechanics in 1998 and PhD in Geological Engineering in 2001. Since 2001, he has worked in the Institute of Geology and Geophysics, Chinese Academy of Sciences, with special attentions to deformation and failure process, and time dependent effects of rocks paid in recent years, including hydraulic fracturing induced by pressured fluids in unconventional oil and gas reservoirs.

Jian Zhou is a post-doctor in the Institute of Geology and Geophysics, Chinese Academy of Sciences. His research interests involve rock mechanics, geological engineering and numerical simulation of hydraulic fracturing. He received his Bachelor's degree in 2008 and $\mathrm{PhD}$ in Geological Engineering in 2013. Since 2013, he worked as a post-doctor in the Institute of Geology and Geophysics, Chinese Academy of Sciences in the area of hydraulic fracturing process of unconventional oil and gas reservoirs.

Zhenhua Han is currently a $\mathrm{PhD}$ candidate in the Institute of Geology and Geophysics, Chinese Academy of Sciences, major in geological engineering. She received her Bachelor's degree in 2013. Since 2013, she worked in the area of hydraulic fracturing process of unconventional oil and gas reservoirs. 


\section{Introduction}

Hydraulic fracturing is a process involving initiation and propagation of an artificial fracture, due to fluid injection in rock. This method has been widely used in energy industry to enhance the recovery of hydrocarbons from tight reservoir rocks, through the creation of hydraulic fractures and coupling of these new higher permeability flow paths with the natural fracture networks in the rock $(\mathrm{Fu}$ et al., 2013; Wang, 2015). In addition, hydraulic fracturing can be applied in fields of the disposal of radioactive waste in the underground spaces (De Laguna et al., 1968), heat production from hot dry rock geothermal reservoirs (Zimmermann et al., 2009, 2010), as well as the measurement of in-situ stresses (Fairhurst, 2003; Haimson and Cornet, 2003; Yokoyama et al., 2014).

Types, geometry and dimensions of hydraulic fractures are critical to assess wellbore stimulation efficiency, so it is very essential to understand mechanism and process of hydraulic fracturing for design and treatment of efficient hydraulic fracturing stimulation. The physical complexity of hydraulic fracturing can be investigated by theoretical analyses, laboratory experiments and numerical modelling, the third one of which has developed rapidly because of its higher efficiency and lower costs. In the past few years, a number of hydraulic fracturing models have been suggested for describing fracture networks in subsurface reservoirs. However, hydraulic fracturing process is still a challenge due to in-situ stresses, discontinuity and anisotropy properties of the rock mass, wellbore geometry, moving fracture boundary, and complex coupling mechanisms among highly pressured fluid and solid materials.

Due to the complexity of the problem, some researches had to consider the rock mass as a homogeneous, isotropic, linear elastic continuum and the fracture geometry as planar, such as the Khristianovic-Geertsma-De Klerk (KGD) model (Perkins and Kern, 1961; Nordgren, 1972) and the PerkinsKern-Nordgren (PKN) model (Khristianovic and Zheltov, 1955; Geertsma, 1969). Such models are highly simplified and idealised under the assumption of linear elastic fracture mechanism (LEFM), which uses a stress intensity factor at the planar fracture tip as fracture propagation criterion.

In recent years, discontinum methods have been utilised to investigate hydraulic fracture propagation in fractured reservoirs, such as the discrete element method (DEM). Based on UDEC modelling, Choi (2012) have studied the shut-in pressure during hydraulic fracturing in rock masses, and the results show that the ambiguous shut-in pressure is mainly related to hydraulic fracture geometries and remote stresses. Using a series of UDEC simulations, Zangeneh et al. (2015) studied three types of interactions (crossing, offset, and arresting) between a hydraulic fracture and natural fracture for different ranges of approach angles and in-situ stress states. Hamidi and Mortazavi (2012, 2014) utilised 3DEC to study the influence of in-situ stress regime, rock mass mechanical properties on hydraulic fracture propagation with different fluid viscosity and injection rates.
A bonded particle model based on particle flow code (PFC) (Itasca Consulting Group, 2008) was also used to model hydraulic fracturing (Hazzard et al., 2002; Al-Busaidi et al., 2005), and the results showed that the model can truly reproduce the physics of fluid injection into lowpermeability formations. Through comparisons with results of the geometry of hydraulic fractures from laboratory experiments and field observations of micro-seismic locations, magnitudes and source mechanisms, Zhao and Young (2011) validated the $\mathrm{PFC}^{2 \mathrm{D}}$ code for modelling hydraulic fracturing. Shimizu et al. (2011) conducted a series of hydraulic fracturing simulations in competent rock by using flow-mechanically coupled $\mathrm{PFC}^{2 \mathrm{D}}$ code, and investigated the influence of the fluid viscosity and particle size distribution.

Current researches were mostly focused on hydraulic fracturing in isotropic medium with a wellbore, with few studies involving perforations or anisotropic medium. An earlier study demonstrated that the main perforation parameters (e.g., length, diameter and orientation) can predict and control the variability of the fracture initiation pressure (FIP) during multistage fracturing treatment (Alekseenko et al., 2012). Based on the extended finite element method (EFEM), Wang (2015) developed a fully coupled non-planar hydraulic fracture propagation model in permeable medium, which is able to model fracture initiation and propagation around a perforated wellbore. Seen from the fracture propagation path and the induced shear stress distribution, it can be noted that the fracture first initiated along the directions of perforations, and then it gradually changes its propagation direction to align itself with the direction of maximum in-situ stress until it hits the simulation boundary.

The laminated heterogeneity of tight reservoirs often produces considerable variability in deformation and strength properties in the directions parallel and perpendicular to the bedding planes. By incorporating the anisotropic elastic deformation and pore hydro-mechanical coupling effects, Li et al. (2015) established a FEM model of fracture initiation from a perforated horizontal wellbore. A sensitivity analysis was proposed to evaluate the effects of the anisotropic mechanical behaviour and in-situ stress conditions on the fracture initiation pressure (FIP) and location of an initial rupture. Only assuming one perforation in transverse section of the wellbore, perforation parameters including perforation density along the wellbore, perforation diameter, and perforation depth, were analysed in elastic anisotropy conditions.

To investigate hydraulic fracturing process in different rock mass conditions, the authors presented a modified fluid-mechanically coupled model in $\mathrm{PFC}^{2 \mathrm{D}}$, which has been well validated by comparison with analytical solution and laboratory tests (Zhou et al., 2016). To show capacity of the modified method, the authors will analyse three groups of geomechanical situations, respectively for isotropic rock mass with a wellbore, laminated reservoir rock with a wellbore, and isotropic medium with a perforated wellbore. 
Although same $\mathrm{PFC}^{2 \mathrm{D}}$ models are utilised, hydraulic fractures may initiate at various locations around wellbore or/and propagate along a various direction due to influences of different in-situ stress ratios, injection ratios, layers' inclinations, perforation parameters, and so on. An orthogonal coordinate system is established in Figure 1, with its origin at the centre of the wellbore, so as to indicate different locations or directions around the wellbore, respectively for the three groups of situations.

\section{Hydraulic fracturing process in an isotropic medium with a wellbore}

To model hydraulic fracturing process in an isotropic medium with a wellbore, the authors will utilise same model as Figure 6 in the sister paper (Zhou et al., 2016), with the model geometry, particles elements and boundary conditions in details described there. The macroscopic and microscopic mechanical parameters used in this study are shown in Table 1 of the sister paper (Zhou et al., 2016). To show general application of the modified $\mathrm{PFC}^{2 \mathrm{D}}$ model, influences of in-situ stress ratio (the ratio of maximum in-situ stress to minimum one) and fluid injection rate were simulated and discussed in this section.

\subsection{The influence of in-situ stress ratio}

The influence of the in-situ stress ratio on hydraulic fracturing process is investigated in a general situation, where the viscosity of the fluid is $1.0 \times 10^{-3} \mathrm{~Pa} \cdot \mathrm{s}$, and the micro-mechanical parameters and initial permeability in the rock models remain unchanged. The stress in $x$-direction $\left(S_{H}\right)$ is kept to be $20 \mathrm{MPa}$, while the stress in $y$-direction $\left(S_{V}\right)$ is varied from $20 \mathrm{MPa}, 15 \mathrm{MPa}$ to $12 \mathrm{MPa}$. Under the assumption that the hydraulic apertures of fluid flow pipes conform to equation (11) in the sister paper (Zhou et al., 2016), the average initial apertures are $4.55 \times 10^{-7} \mathrm{~m}$, $4.98 \times 10^{-7} \mathrm{~m}$ and $5.33 \times 10^{-7} \mathrm{~m}$, respectively for the in-situ stress ratios 1.0, 1.33 and 1.67. With increasing fluid pressure in the domains, the aperture can reach to $1.03 \times 10^{-6} \mathrm{~m}$ when the bonding stress condition between particles is tensile.

Figure 1 Graphical representation of $\mathrm{PFC}^{2 \mathrm{D}}$ model partially near the wellbore, (a) isotropic rock mass with a wellbore, (b) laminated reservoir rock with a wellbore and (c) isotropic medium with a perforated wellbore (see online version for colours)

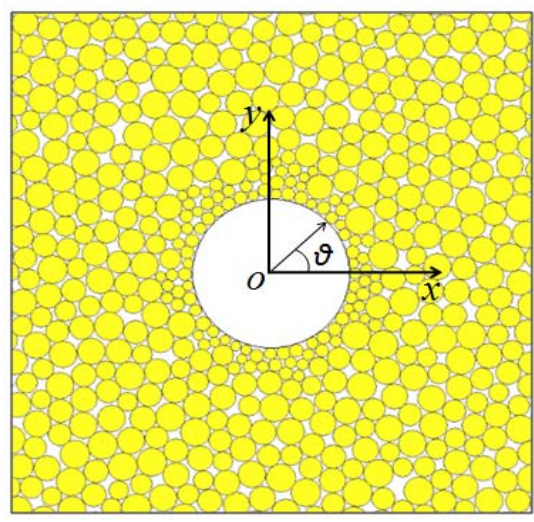

(a)

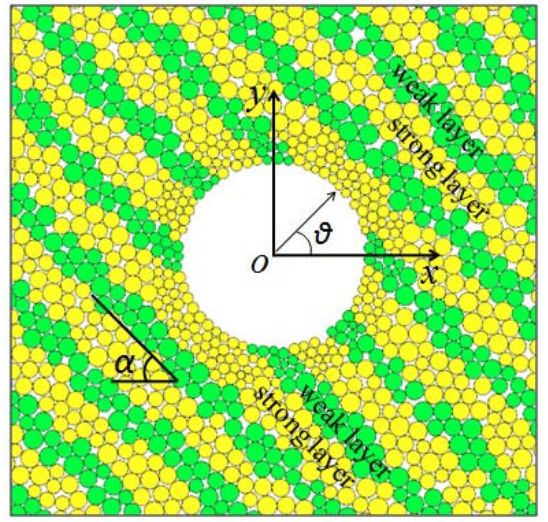

(b)

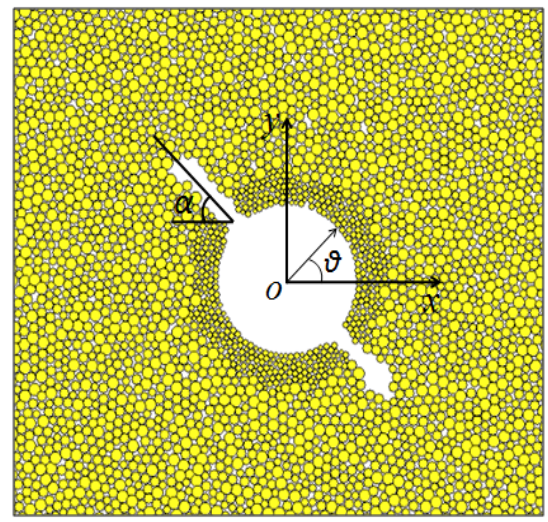

(c)

Table 1 Modelling results of hydraulic fracturing around a wellbore in an isotropic medium under different in-situ stress ratios and injection ratios

\begin{tabular}{|c|c|c|c|c|c|c|c|}
\hline $\begin{array}{l}\text { Case } \\
\text { number }\end{array}$ & $\begin{array}{l}\text { Fluid } \\
\text { viscosity } \\
(\mathrm{Pa} \cdot \mathrm{s})\end{array}$ & $\begin{array}{c}\text { Injection } \\
\text { ratio } \\
\left(\mathrm{m}^{3} / \mathrm{s}\right)\end{array}$ & $\begin{array}{c}\text { In-situ stress } \\
\text { ratio } S_{H} / S_{V} \\
(\mathrm{MPa} / \mathrm{MPa})\end{array}$ & $\begin{array}{c}\text { Breakdown } \\
\text { pressure } \\
(\mathrm{MPa})\end{array}$ & $\begin{array}{c}\text { Number of } \\
\text { macroscopic } \\
\text { fractures }\end{array}$ & $\begin{array}{c}\text { Location of } \\
\text { fracture } \\
\text { initiation }\end{array}$ & $\begin{array}{l}\text { Description of fracture } \\
\text { propagation direction }\end{array}$ \\
\hline 1 & $1.0 \times 10^{-3}$ & $1.0 \times 10^{-5}$ & $1.00(20 / 20)$ & 43.5 & 2 & $100^{\circ}, 170^{\circ}$ & 1, 2. Vertical \\
\hline 2 & & & $1.33(20 / 15)$ & 33.5 & 2 & $25^{\circ}, 155^{\circ}$ & 1, 2. Horizontal \\
\hline 3 & & & $1.67(20 / 12)$ & 27.1 & 2 & $30^{\circ}, 180^{\circ}$ & 1, 2. Horizontal \\
\hline 4 & & $1.0 \times 10^{-4}$ & $1.00(20 / 20)$ & 46.5 & 3 & $80^{\circ}, 160^{\circ}, 340^{\circ}$ & 1,2. Radial \\
\hline 5 & & & $1.33(20 / 15)$ & 44.1 & 2 & $80^{\circ}, 160^{\circ}$ & $\begin{array}{l}1,2 . \text { Radial and then } \\
\text { transition to horizontal }\end{array}$ \\
\hline 6 & & & $1.67(20 / 12)$ & 37.6 & 2 & $30^{\circ}, 160^{\circ}$ & 1, 2. Horizontal \\
\hline 7 & & $5.0 \times 10^{-4}$ & $1.00(20 / 20)$ & 65.3 & 4 & $\begin{array}{c}80^{\circ}, 135^{\circ}, 160^{\circ}, \\
340^{\circ}\end{array}$ & 1, 2. Radial \\
\hline
\end{tabular}


To indicate influences of in-situ stress ratio and injection ratio on initiation and propagation of hydraulic fractures, seven cases of parameter combination are designed and modelling results presented in Table 1, Figures 2 and 3.

Many researches demonstrated that hydraulic fractures initiate and propagate along a preferred fracturing plane or path (PFP), which is the direction of least resistance and generally along maximum in-situ stress (Wang, 2015). As shown in Figure 1, some weak points often exist around the wellbore during construction of the $\mathrm{PFC}^{2 \mathrm{D}}$ model, where may be locations of fracture initiation dependent on parameter combination applied in different cases (Table 1). Because the initial onset of fracture is influenced by wellbore geometry, local stress concentration and rock strength, if the fracture initiation is misaligned with the direction of PFP, the fracture will reorient itself to propagate in the direction of least resistance (Wang, 2015). As shown in Figures 2 and 3, fracture propagation will align or gradually reorient to the direction of maximum horizontal in-situ stress in all cases of in-situ stress ratio larger than 1.0 .

Under same fluid viscosity $1.0 \times 10^{-3} \mathrm{~Pa} \cdot \mathrm{s}$ and injection ratio $1.0 \times 10^{-5} \mathrm{~m}^{3} / \mathrm{s}$, the hydraulic fracture has earlier initiation and faster propagation in cases of larger in-situ stress ratio, and its breakdown pressure decrease as increasing in-situ stress ratio of from 1.00 to 1.67 (Table 1).
Seen from Figures 2 and 3, the fractures become straighter for larger in-situ stress ratio.

When the larger in-situ stress ratio is applied, only two macroscopic fractures occurred along the PFP direction, respectively on both sides of the wellbore. Moreover, the number and location of the fractures will also be influenced by other factors (such as fluid injection rate), especially in condition of smaller differential remote stresses (such as hydrostatic confining pressures).

\subsection{The influence of fluid injection rate}

Previous studies have proven an important role of fluid injection rate in hydraulic fracturing (King, 2010), which is also clearly indicated by comparison between Figure 2(a) and Figure 3(a), and Figure 2(b) and Figure 3(b). To investigate the influence of injection rate on hydraulic fracturing characteristics, the authors utilise three different injection rates with unchanged fluid viscosity and hydrostatic pressure, as shown in cases 1,4 and 7 in Table 1 . The viscosity of fluid is $1.0 \times 10^{-3} \mathrm{~Pa} \cdot \mathrm{s}$, and the confining pressure in both $\mathrm{x}$-direction and $\mathrm{y}$-direction are $20 \mathrm{MPa}$. Three injection rates, $1.0 \times 10^{-5} \mathrm{~m}^{3} / \mathrm{s}$, $1.0 \times 10^{-4} \mathrm{~m}^{3} / \mathrm{s}$ and $5.0 \times 10^{-4} \mathrm{~m}^{3} / \mathrm{s}$, are respectively applied in modelling of hydraulic fracturing. The modelling results are presented in Figure 4.

Figure 2 Hydraulic fracture distribution with a fluid viscosity of $1.0 \times 10^{-3} \mathrm{~Pa} \cdot \mathrm{s}$ and an injection rate of $1.0 \times 10^{-5} \mathrm{~m}^{3} / \mathrm{s}$ under different in-situ stress ratios, (a) $S_{H} / S_{V}=1.00(20 \mathrm{MPa} / 20 \mathrm{MPa})$ (b) $S_{H} / S_{V}=1.33(20 \mathrm{MPa} / 15 \mathrm{MPa})$ (c) $S_{H} / S_{V}=1.67(20 \mathrm{MPa} / 12 \mathrm{MPa})$ (see online version for colours)

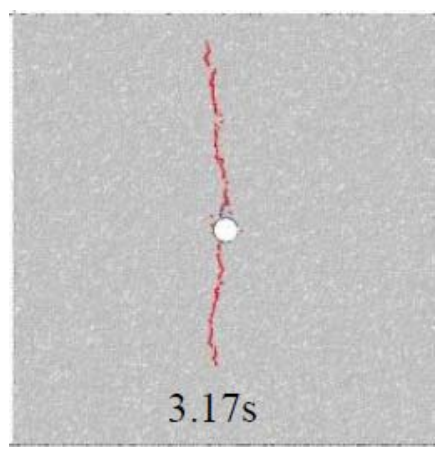

(a)

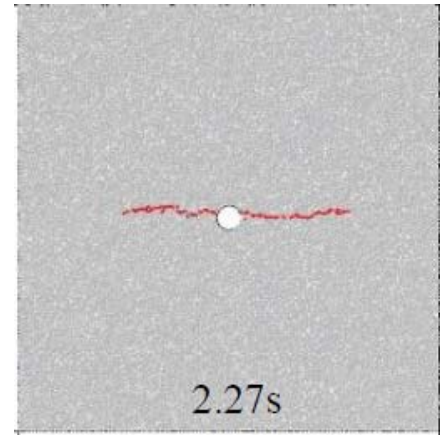

(b)

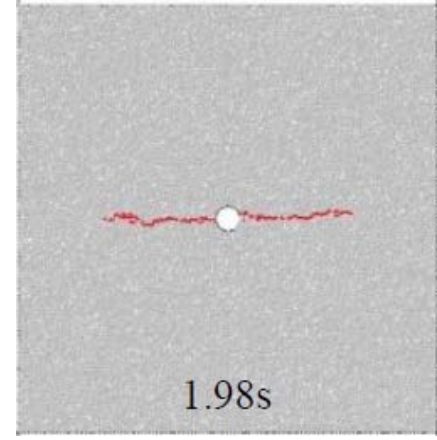

(c)

Figure 3 Hydraulic fracture distribution with a fluid viscosity of $1.0 \times 10^{-3} \mathrm{~Pa} \cdot \mathrm{s}$ and an injection rate of $1.0 \times 10^{-4} \mathrm{~m}^{3} / \mathrm{s}$ under different in-situ stress ratios, (a) $S_{H} / S_{V}=1.00(20 \mathrm{MPa} / 20 \mathrm{MPa})$ (b) $S_{H} / S_{V}=1.33(20 \mathrm{MPa} / 15 \mathrm{MPa})$ (c) $S_{H} / S_{V}=1.67(20 \mathrm{MPa} / 12 \mathrm{MPa})$ (see online version for colours)

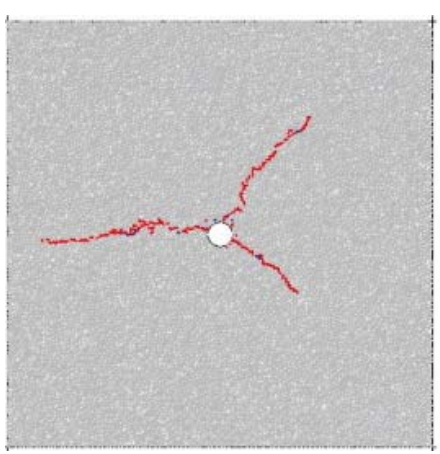

(a)

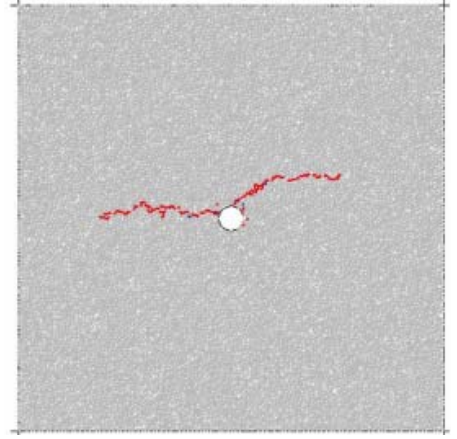

(b)

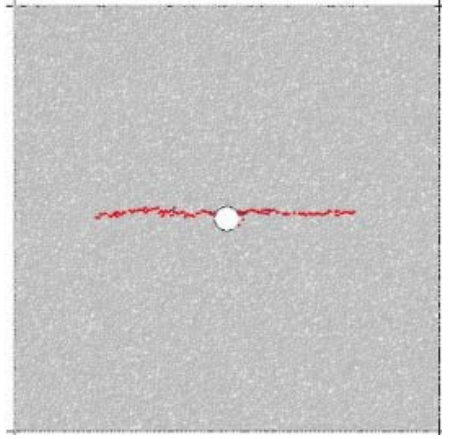

(c) 
Figure 4 Wellbore pressure histories and fracture distribution in the modelling with a fluid viscosity of $1.0 \times 10^{-3} \mathrm{~Pa} \cdot \mathrm{s}$ and a hydrostatic pressure of $20 \mathrm{MPa}$, under different injection rates, (a) $1.0 \times 10^{-5} \mathrm{~m}^{3} / \mathrm{s}$ (b) $1.0 \times 10^{-4} \mathrm{~m}^{3} / \mathrm{s}$ (c) $5.0 \times 10^{-4} \mathrm{~m}^{3} / \mathrm{s}$ (see online version for colours)
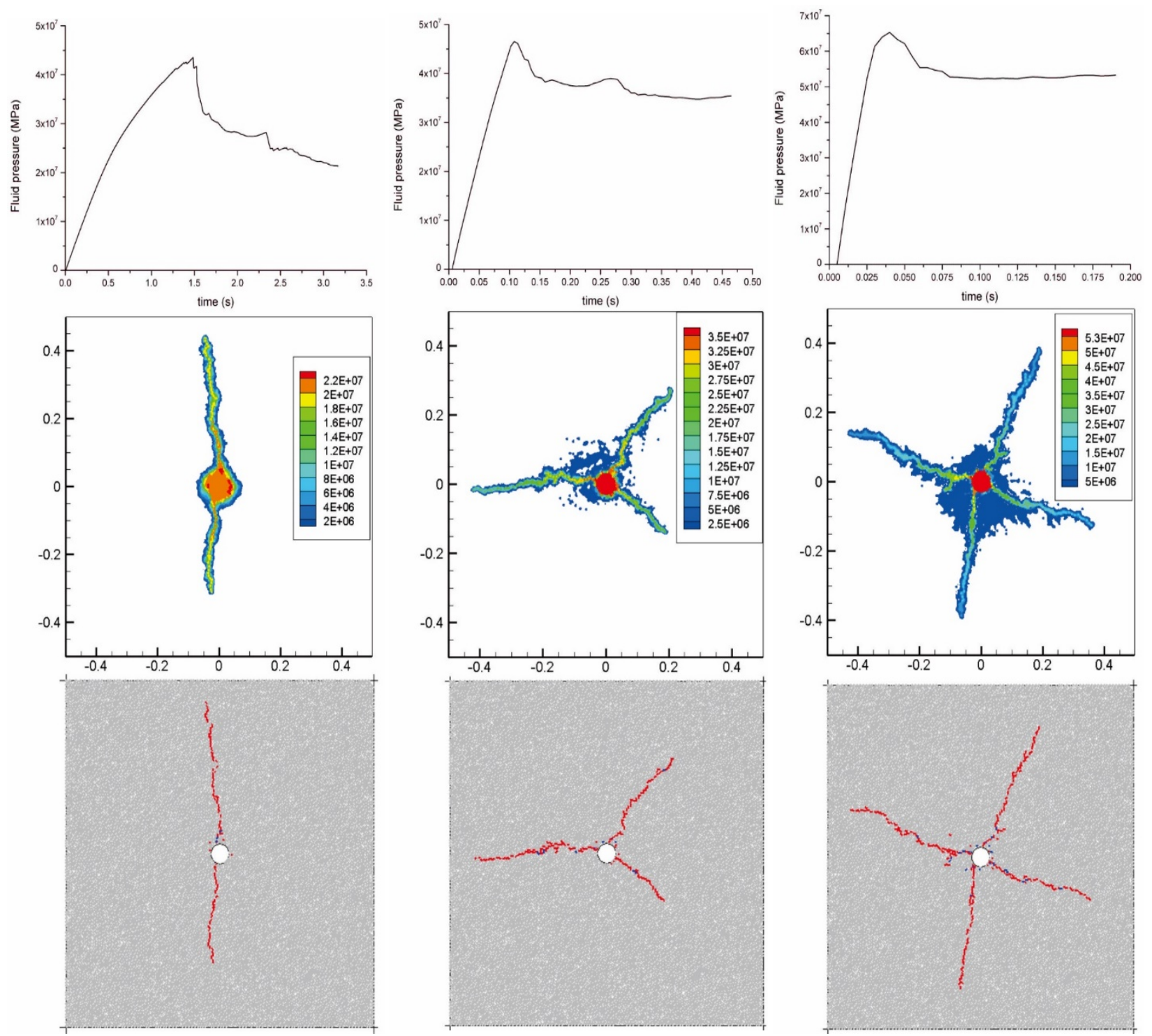

(a)

(b)

(c)

As we know, faster fluid injection implies a higher loading rate applied around the wellbore, which will result in higher strength similar to compressive tests of rock specimens applied with dynamic loads in the laboratory. Because stresses in the solid skeleton induced by the wellbore pressure cannot immediately adjusted, higher fluid injection rate will lead to a larger breakdown pressure in hydraulic fracturing. As seen from Figure 4, the breakdown pressures (respectively 43.6 MPa, 46.5 $\mathrm{MPa}$ and 65.3 $\mathrm{MPa}$ ) increases as the injection rate increases, and pore pressure fields become more and more pronounced. In addition, more hydraulic fractures were produced by means of higher injection rates, which is consistent with observations made in previous researches.

From comparisons among Figures 2, 3 and 4, complex fracture network will be created in cases of smaller differential remote stresses and higher fluid injection ratios.

\section{Hydraulic fracturing process in a laminated rock with a wellbore}

The laminated rock has anisotropic properties in its deformation and strength, and shale is the best representation of anisotropy among various laminated sedimentary rock systems. The laminated heterogeneity of shale results in high variability in mechanical properties along orientations perpendicular and parallel to the bedding, with a difference varying from $100 \%$ to $400 \%$ (Gautam, 2004). In this study, rock specimens for microscopic parameters calibration were taken from the shale outcrops of the Longmaxi Formation in Xiliao, Shizhu County, which is the natural extension of shale formations in Pengshui shale gas block. These shale specimens are typical laminated rock with different inclination angles. To model hydraulic fracturing process in an anisotropic medium with a wellbore, a series of transversely isotropic rock model 
were constructed by embedding weak layer in rock matrix (i.e., strong layer), same as Figure 11 in the sister paper (Zhou et al., 2016). The microscopic mechanical parameters used in this study are shown in Table 2 of the sister paper (Zhou et al., 2016).

In this section, three types of effects will be investigated for hydraulic fracturing process, i.e., effects of weak layer, in-situ stress ratio and fluid injection rate. To reflect the first effect completely, a hydrostatic pressure of $20 \mathrm{MPa}$ is applied in the modelling. For effects of differential remote stresses, three confining boundary conditions are applied in modelling, i.e., in-situ stress ratios of 1.25 $\left(S_{H} / S_{V}=25 \mathrm{MPa} / 20 \mathrm{MPa}\right), 1.50\left(S_{H} / S_{V}=30 \mathrm{MPa} / 20 \mathrm{MPa}\right)$ and $2.0\left(S_{H} / S_{V}=40 \mathrm{MPa} / 20 \mathrm{MPa}\right)$.

\subsection{The effects of weak layer}

As shown in the first seven cases in Table 2, seven models are built to simulate of fracture initiation and propagation in laminated rock, with a hydrostatic pressure of $20 \mathrm{MPa}$ applied. The seven models are constituted by strong layers and weak layers with inclination angles $\alpha$ of $0^{\circ}, 15^{\circ}, 30^{\circ}$, $45^{\circ}, 60^{\circ}, 75^{\circ}$ and $90^{\circ}$, respectively (Figure 5 ). The permeability of models is assumed to be $1 \times 10^{-17} \mathrm{~m}^{2}$ at $0 \mathrm{MPa}$ confining pressure, and with confining pressure increasing it will reduce to $1 \times 10^{-19} \mathrm{~m}^{2}$ at infinite.

Comparing fracture distribution in these cases, a basic conclusion can be drawn that all fractures initiated in weak layers or interfaces of two different layers around the wellbore. The breakdown pressures are $73.5 \mathrm{MPa}, 66.1$ $\mathrm{MPa}$, 66.6 MPa, 77.1 MPa, 61.1 MPa, 64.6 MPa and 59.0 $\mathrm{MPa}$, respectively for models with dip angle of $0^{\circ}, 15^{\circ}, 30^{\circ}$, $45^{\circ}, 60^{\circ}, 75^{\circ}$ and $90^{\circ}$. If initial cracking directions are not along the layers, this will result in higher breakdown pressure, as shown in Figures 5(a), 5(c) and 5(d). Although several weaker locations exist along the wellbore in the model, only two initial cracks will finally develop to be two macroscopic fractures, respectively. When the initial cracking has a bigger intersection angle with a bedding plane, the fractures often propagates by crossing the bedding plane.

As indicated in Figure 5, three fractures patterns may be macroscopically summarised as follows, i.e.,

1 two wings crossing the layers

2 two wings along the weaker layers

3 one wing crossing the layers and the other along one weaker layer.

In the first pattern, two fractures penetrate both weak and strong layers from their initiation to propagation, such as Figures 5(c) and 5(d). In the second pattern, two fractures initiate and propagate in weak layers or reorient themselves gradually along the layers, as shown in Figures 5(b), 5(e) and $5(\mathrm{~g})$. In the third pattern, one fracture develops along the weak layer, and the other intersects different layers, such as Figures 5(a) and 5(f).

Figure 5 The fractures distribution in laminated rock having weak layers of different dip angle, applied with a hydrostatic pressure of $20 \mathrm{MPa}$, fluid viscosity of $1.0 \times 10^{-3} \mathrm{~Pa} \cdot \mathrm{s}$ and injection rate of $2.0 \times 10^{-5}$, (a) $0^{\circ}(73.5 \mathrm{MPa})$ (b) $15^{\circ}(66.1 \mathrm{MPa})(\mathrm{c}) 30^{\circ}(66.6$ $\mathrm{MPa})(\mathrm{d}) 45^{\circ}(77.1 \mathrm{MPa})(\mathrm{e}) 60^{\circ}(61.1 \mathrm{MPa})(\mathrm{f}) 75^{\circ}(64.6 \mathrm{MPa})(\mathrm{g}) 90^{\circ}(59.0 \mathrm{MPa})$ (see online version for colours)

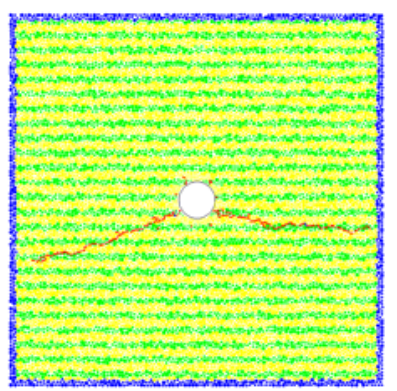

(a)

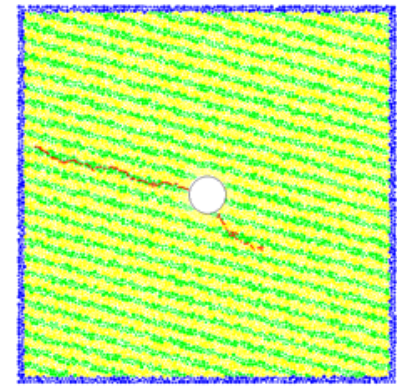

(b)

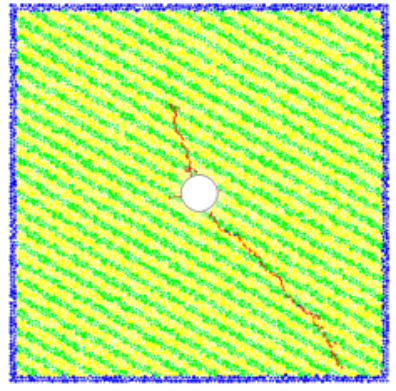

(c)

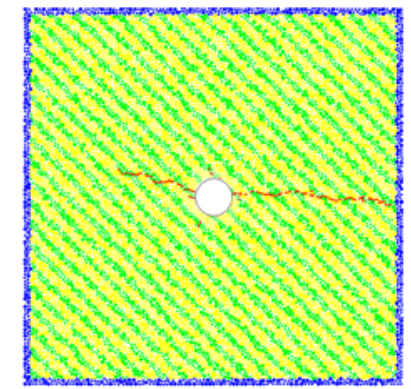

(d)

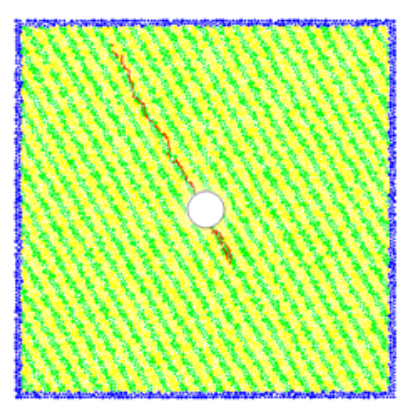

(e)

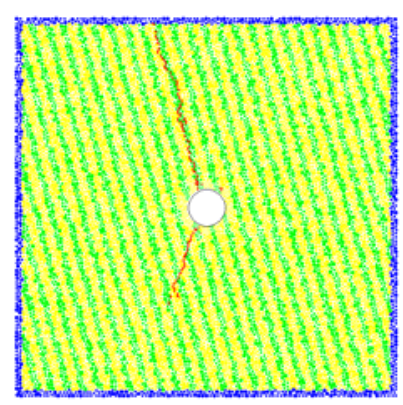

(f)

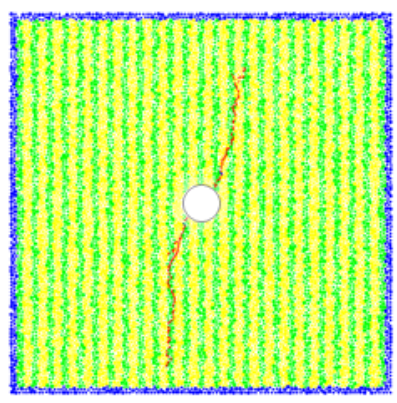

(g)

Note: The values in brackets are breakdown pressures for each case. 
Table 2 Modelling results of hydraulic fracturing around a wellbore in an anisotropic medium under different in-situ stress ratios, injection ratios and dip angles of bedding plane when fluid viscosity is $1.0 \times 10^{-3} \mathrm{~Pa} \cdot \mathrm{s}$

\begin{tabular}{|c|c|c|c|c|c|c|c|}
\hline $\begin{array}{l}\text { Case } \\
\text { number }\end{array}$ & $\begin{array}{l}\text { Injection } \\
\text { rate } \\
\left(\mathrm{m}^{3} / \mathrm{s}\right)\end{array}$ & $\begin{array}{l}\text { In-situ stress } \\
\text { ratios } S_{H} / S_{V} \\
(\mathrm{MPa} / \mathrm{MPa})\end{array}$ & $\begin{array}{l}\text { Dip angles } \\
\text { of bedding } \\
\text { planes }\end{array}$ & $\begin{array}{l}\text { Breakdown } \\
\text { pressure } \\
(\mathrm{MPa})\end{array}$ & $\begin{array}{l}\text { Number of } \\
\text { macroscopic } \\
\text { fractures }\end{array}$ & $\begin{array}{l}\text { Location of } \\
\text { fracture initiation }\end{array}$ & $\begin{array}{l}\text { Description of fracture } \\
\text { propagation direction }\end{array}$ \\
\hline 1 & $2.0 \times 10^{-5}$ & 1.00 & $0^{\circ}$ & 73.5 & 2 & $225^{\circ}, 320^{\circ}$ & 1. RCL; 2. PCWL \\
\hline 2 & & $(20 / 20)$ & $15^{\circ}$ & 66.1 & 2 & $140^{\circ}, 290^{\circ}$ & 1. RWL; 2. RCL \\
\hline 3 & & & $30^{\circ}$ & 66.6 & 2 & $100^{\circ}, 290^{\circ}$ & 1, 2. RCL \\
\hline 4 & & & $45^{\circ}$ & 77.1 & 2 & $140^{\circ}, 360^{\circ}$ & 1,2. RCL \\
\hline 5 & & & $60^{\circ}$ & 61.1 & 2 & $120^{\circ}, 285^{\circ}$ & 1, 2. RWL \\
\hline 6 & & & $75^{\circ}$ & 64.6 & 2 & $110^{\circ}, 250^{\circ}$ & 1. RWL; 2. RCL \\
\hline 7 & & & $90^{\circ}$ & 59.0 & 2 & $60^{\circ}, 240^{\circ}$ & 1, 2. PCWL \\
\hline 8 & & 1.25 & $15^{\circ}$ & 69.5 & 2 & $160^{\circ}, 340^{\circ}$ & 1, 2. RWL \\
\hline 9 & & $(25 / 20)$ & $30^{\circ}$ & 71.1 & 2 & $10^{\circ}, 160^{\circ}$ & 1. RCL; 2. HCL \\
\hline 10 & & & $60^{\circ}$ & 72.0 & 2 & $120^{\circ}, 290^{\circ}$ & $\begin{array}{l}\text { 1. RWL and then crossing layers; } \\
\text { 2. RWL }\end{array}$ \\
\hline 11 & & & $90^{\circ}$ & 64.4 & 2 & $60^{\circ}, 240^{\circ}$ & 1,2. RCL \\
\hline 12 & & 1.50 & $15^{\circ}$ & 61.3 & 2 & $160^{\circ}, 340^{\circ}$ & 1, 2. RWL and then SHCL \\
\hline 13 & & $(30 / 20)$ & $30^{\circ}$ & 62.2 & 2 & $10^{\circ}, 160^{\circ}$ & 1. RCL and then HCL; 2. HCL \\
\hline 14 & & & $60^{\circ}$ & 74.3 & 2 & $180^{\circ}, 340^{\circ}$ & $\begin{array}{l}\text { 1. RWL; } 2 . \mathrm{RCL} \text { and then } \\
\text { horizontally crossing layers }\end{array}$ \\
\hline 15 & & & $90^{\circ}$ & 66.5 & 2 & $60^{\circ}, 240^{\circ}$ & 1, 2. fracture initiation and then $\mathrm{HCL}$ \\
\hline 16 & & 2.00 & $15^{\circ}$ & 57.3 & 2 & $160^{\circ}, 340^{\circ}$ & 1, 2. RWL and then SHCL \\
\hline 17 & & $(40 / 20)$ & $30^{\circ}$ & 63.8 & 2 & $10^{\circ}, 160^{\circ}$ & 1. RCL and then HCL layer; 2. HCL \\
\hline 18 & & & $60^{\circ}$ & 71.6 & 2 & $180^{\circ}, 340^{\circ}$ & 1,2. HCL \\
\hline 19 & & & $90^{\circ}$ & 72.1 & 2 & $60^{\circ}, 180^{\circ}$ & $\begin{array}{l}\text { 1. fracture initiation and transition to } \\
\text { HCL; } 2 \text {. SHCL }\end{array}$ \\
\hline 20 & $5.0 \times 10^{-5}$ & $\begin{array}{c}1.50 \\
(30 / 20)\end{array}$ & $15^{\circ}$ & 72.2 & 2 & $220^{\circ}, 340^{\circ}$ & $\begin{array}{l}\text { 1. fracture initiation and then along } \\
\text { weak layer; } 2 \text {. RWL and then SHCL }\end{array}$ \\
\hline 21 & & & $30^{\circ}$ & 64.6 & 2 & $150^{\circ}, 330^{\circ}$ & 1, 2. RWL, partially HCL \\
\hline 22 & & & $60^{\circ}$ & 78.3 & 2 & $45^{\circ}, 180^{\circ}$ & $\begin{array}{l}\text { 1. CPL, partially curved transition; } 2 \text {. } \\
\text { CPL and curved transition to HCL }\end{array}$ \\
\hline 23 & & & $90^{\circ}$ & 68.6 & 2 & $60^{\circ}, 240^{\circ}$ & $\begin{array}{l}1,2 . \mathrm{RCL} \text { and then curved transition } \\
\text { to HCL }\end{array}$ \\
\hline 24 & $1.0 \times 10^{-4}$ & $\begin{array}{c}1.50 \\
(30 / 20)\end{array}$ & $15^{\circ}$ & 72.0 & 3 & $135^{\circ}, 220^{\circ}, 290^{\circ}$ & $\begin{array}{l}\text { 1. radial small fracture; } 2,3 . \mathrm{RCL} \\
\text { and rapid transition along weak layer }\end{array}$ \\
\hline 25 & & & $30^{\circ}$ & 79.4 & 2 & $10^{\circ}, 135^{\circ}$ & $\begin{array}{l}\text { 1. HCL; 2. radial initiation and rapid } \\
\text { transition to SHCL }\end{array}$ \\
\hline 26 & & & $60^{\circ}$ & 76.8 & 3 & $60^{\circ}, 180^{\circ}, 290^{\circ}$ & $\begin{array}{l}\text { 1. RCL and then curved transition to } \\
\text { HCL; } 2 . \mathrm{HCL} ; 3 . \text {, radial smaller } \\
\text { fracture along weak layer and with } \\
\text { partial crossing }\end{array}$ \\
\hline 27 & & & $90^{\circ}$ & 73.3 & 2 & $60^{\circ}, 240^{\circ}$ & $\begin{array}{l}1,2 . \mathrm{RCL} \text { and then curved transition } \\
\text { to SHCL }\end{array}$ \\
\hline 28 & $5.0 \times 10^{-4}$ & $\begin{array}{c}1.50 \\
(30 / 20)\end{array}$ & $15^{\circ}$ & 96.1 & 4 & $\begin{array}{c}60^{\circ}, 135^{\circ}, 220^{\circ}, \\
290^{\circ}\end{array}$ & $1,2,3,4 . \mathrm{RCL}$ \\
\hline 29 & & & $30^{\circ}$ & 94.5 & 3 & $60^{\circ}, 135^{\circ}, 290^{\circ}$ & $\begin{array}{l}\text { 1. RCL and then turning direction; } \\
\text { 2. RWL; 3. RCL }\end{array}$ \\
\hline 30 & & & $60^{\circ}$ & 95.6 & 3 & $60^{\circ}, 170^{\circ}, 290^{\circ}$ & 1, 2. RCL; 3. RWL \\
\hline 31 & & & $90^{\circ}$ & 101.9 & 3 & $60^{\circ}, 135^{\circ}, 290^{\circ}$ & $1,2,3 \mathrm{RCL}$ \\
\hline
\end{tabular}

Notes: RCL: radial fracture crossing layers; RWL: radial fracture along weak layer; HCL: horizontally crossing layers; SHCL: sub-horizontally crossing layers; PCWL: partial crossing and then along weak layer; CPL: crossing perpendicular to layers. 
As mentioned above, hydraulic fractures initiated all in weak layer and propagated easier if initial cracking direction aligns the layer or intersects it with a small included angle. In other words, the weak layer is a preferred direction of hydraulic fracturing propagation when the models are applied with hydrostatic pressure or smaller in-situ stress ratios.

\subsection{The effects of in-situ stress ratio}

To investigate the effects of in-situ stress ratio on the hydraulic fracture initiation and propagation in laminated rock, a series of numerical models are constructed in the reverse fault stress regime (i.e., $S_{H}>S_{V}$ ). The in-situ stress in vertical direction $\left(S_{V}\right)$ is kept to be $20 \mathrm{MPa}$, while the stress in horizontal direction $\left(S_{H}\right)$ is varied between $25 \mathrm{MPa}$, $30 \mathrm{MPa}$ and $40 \mathrm{MPa}$, respectively. Under the assumption that the hydraulic apertures of fluid flow pipes conform to equation (12) in the sister paper (Zhou et al., 2016), the average initial apertures in these models are $4.62 \times 10^{-7} \mathrm{~m}$, $4.23 \times 10^{-7} \mathrm{~m}$ and $4.03 \times 10^{-7} \mathrm{~m}$ under above confining situations, respectively. With increasing fluid pressure in the models, the aperture can reach to $1.03 \times 10^{-6} \mathrm{~m}$ when the bonding stress condition between particles is tensile.

As shown in Table 2, different situations of in-situ stress ratios were modelled under the fluid viscosity of $1.0 \times 10^{-3}$ $\mathrm{Pa} \cdot \mathrm{s}$ and the injection rate of $2.0 \times 10^{-5} \mathrm{~m}^{3} / \mathrm{s}$, in which cases 8 to 11 are for the ratio $1.25\left(S_{H} / S_{V}=25 \mathrm{MPa} / 20 \mathrm{MPa}\right)$, cases 12 to 15 for the ratio $1.50\left(S_{H} / S_{V}=30 \mathrm{MPa} / 20 \mathrm{MPa}\right)$, and cases 16 to 19 for the ratio $2.00\left(S_{H} / S_{V}=40 \mathrm{MPa} / 20\right.$ $\mathrm{MPa})$. There are totally four different in-situ stress ratios if considering the ratio $1.00\left(S_{H} / S_{V}=20 \mathrm{MPa} / 20 \mathrm{MPa}\right)$ for the cases 1 to 7 in the Table 2. From modelling results of cases 1 to 19 , one can find that initiation and propagation of hydraulic fractures will be controlled by both in-situ stress ratios and anisotropic properties of the laminated rock.

The modelling results indicate that major fractures in laminated models generally start in the weak layers around the injection wellbores, except models for vertical bedding plane (i.e., cases 11, 15 and 19). When strong layers expose around the wellbore in the vertical bedding plane model, and horizontal in-situ stress is maximum one, fractures will initiate in the strong layers due to enough stress concentrations. This is different from the situations of hydrostatic pressures where anisotropy properties of the laminated rock play a main role in fracture initiation and propagation.

To compare breakdown pressures among models with different maximum in-situ stresses, relative breakdown pressure is defined as a ratio of breakdown pressure to maximum in-situ stress in a model. As shown in Figure 6, relative breakdown pressure decrease as an increase of in-situ stress ratios of from 1.0 to 2.0, which can be observed in the models with any dip angles of bedding planes. High in-situ stress ratios will easily induce tensile or shear stress concentration along the wellbore, which promotes occurrence of fracture initiation with a lower fluid pressure. This is a reason why relative breakdown pressures have a greater fluctuation in cases of different layers' inclinations, with hydrostatic pressures applied in the laminated rock models. The authors think that, as in-situ stress ratios increase, the effects of weak layer will decrease and the fluctuation of relative breakdown pressure will also become smaller, as shown in Figure 6.

Figure 6 Relative breakdown pressures for hydraulic fractures around a wellbore in an anisotropic medium under different in-situ stress ratios (ISR) and layers' inclinations when fluid injection rate is $2.0 \times 10^{-5} \mathrm{~m}^{3} / \mathrm{s}$ and fluid viscosity is $1.0 \times 10^{-3} \mathrm{~Pa} \cdot \mathrm{s}$ (see online version for colours)

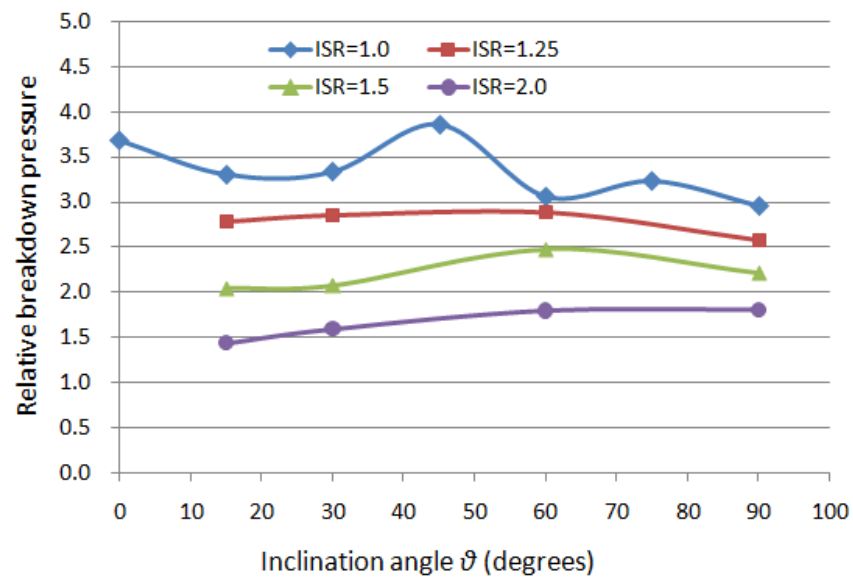

With increasing in-situ stress ratio of from 1.0 to 2.0, hydraulic fractures propagation will be along or reorient rapidly from initial cracking direction to the preferred fracture path (PFP). The PFP will be along the weak layer in cases of smaller in-situ stress ratios, while along maximum in-situ stress in cases of bigger in-situ stress ratios. As shown in Figure 7, two hydraulic fractures propagate along the weak layer under hydrostatic pressure, while their initiation changed to be at maximum tensile stress concentrations and their propagation approached to the directions of maximum horizontal in-situ stress as increasing in-situ stress ratio. Two types of effects have been clearly indicated in Figure 7, in which weak layers play a main role in cases of hydrostatic pressure [Figure 7(a)] or smaller in-situ stress ratio [Figure 7(b)], and maximum in-situ stress will control fracture initiation location and fracture propagation direction in cases of larger in-situ stress ratios [Figures 7(c) and 7(d)].

As described above, hydraulic fracturing process is controlled by a combination of rock anisotropy and differential remote stress in the laminated rock models. Moreover, it can be theoretically and practically analysed that the weak layers will play an increasing role in initiation and propagation of hydraulic fractures, compared with effects of in-situ stress ratios, as anisotropic degree of the laminated rock increases. 
Figure 7 Hydraulic fracture distributions in laminated models with a layer inclination of $60^{\circ}$, having an injection rate of $2.0 \times 10^{-5} \mathrm{~m}^{3} / \mathrm{s}$ and fluid viscosity of $1.0 \times 10^{-3} \mathrm{~Pa} \cdot \mathrm{s}$, in cases of different in-situ stress ratios, (a) $1.0\left(S_{H} / S_{V}=20 \mathrm{MPa} / 20 \mathrm{MPa}\right)$, (b) $1.25\left(S_{H} / S_{V}=25 \mathrm{MPa} / 20 \mathrm{MPa}\right)$, (c) $1.5\left(S_{H} / S_{V}=30 \mathrm{MPa} / 20 \mathrm{MPa}\right)$, and (d) $2.0\left(S_{H} / S_{V}=40 \mathrm{MPa} / 20 \mathrm{MPa}\right)$ (see online version for colours)

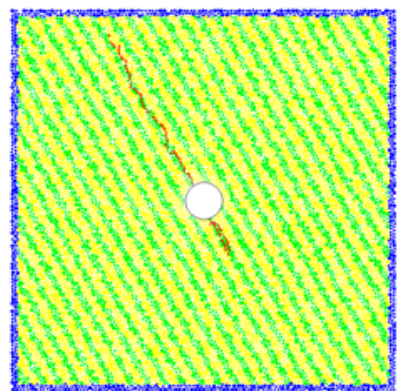

(a)

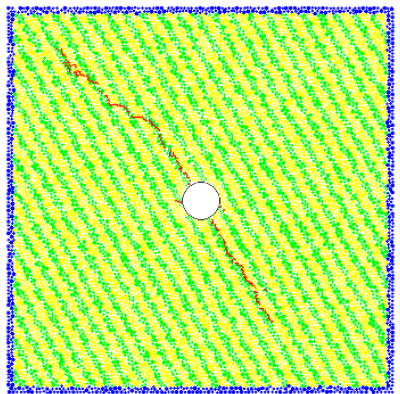

(b)

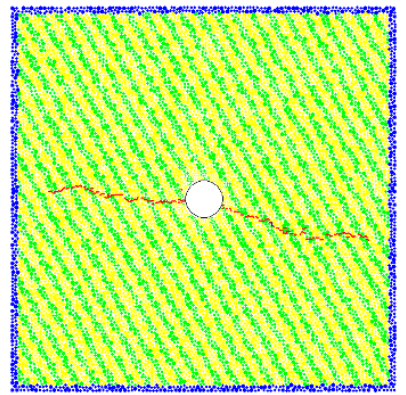

(c)

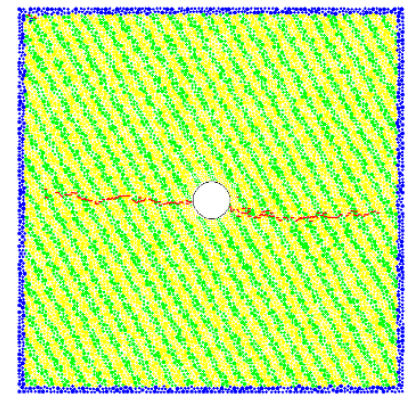

(d)

\subsection{The effects of fluid injection rate}

To investigate effects of fluid injection rate on hydraulic fracturing characteristics, three levels of injection rates 5.0 $\times 10^{-5} \mathrm{~m}^{3} / \mathrm{s}, 1.0 \times 10^{-4} \mathrm{~m}^{3} / \mathrm{s}$ and $5.0 \times 10^{-4} \mathrm{~m}^{3} / \mathrm{s}$, are respectively applied in the laminated rock models. The viscosity of fluid is $1.0 \times 10^{-3} \mathrm{~Pa} \cdot \mathrm{s}$, and the confining pressure in horizontal direction and vertical direction are $30 \mathrm{MPa}$ and $20 \mathrm{MPa}$ respectively. To show anisotropic effects of the weak layers, four inclination angles (respectively $15^{\circ}, 30^{\circ}, 60^{\circ}$ and $90^{\circ}$ ) are considered in the modelling for each injection rate. The modelling results are presented in Table 2 and Figure 8.

For a lower injection rate, initial cracks always occur in weak layers, and their directions will be along the layers or intersect them with a smaller angle, as shown in Figure 8(a). As the injection rates increase from $2.0 \times 10^{-5} \mathrm{~m}^{3} / \mathrm{s}$ to $1.0 \times 10^{-4} \mathrm{~m}^{3} / \mathrm{s}$, some initial cracks may occur in the strong layers, or cross the layers by bigger intersection angles, as shown in Figures 8(b) and 8(c). Seen from Figure 8, the number of initial cracks will increase as increasing injection rates, with more potential fractures developed to be macroscopic ones.

As shown in Figure 9, relative breakdown pressures will change due to different layer inclination angles and anisotropy of the laminated rock. For three lower injection rates of $2.0 \times 10^{-5} \mathrm{~m}^{3} / \mathrm{s}, 5.0 \times 10^{-5} \mathrm{~m}^{3} / \mathrm{s}$ and $1.0 \times 10^{-4} \mathrm{~m}^{3} / \mathrm{s}$, the relative breakdown pressures have no obvious differences on the whole from each other, but they are far below those in case of the highest injection rate of $5.0 \times 10^{-4} \mathrm{~m}^{3} / \mathrm{s}$. It is reasonably considered that fracture initiation will be influenced simultaneously by effects of weak layers, in-situ stress ratios and fluid injection rates. When the injection rate increase to some degree, its effects will become main one compared with the other two effects. This can be proven by more macroscopic fractures, radial

and straight propagation paths in cases of injection rates of $5.0 \times 10^{-4} \mathrm{~m}^{3} / \mathrm{s}$, as shown in Figure $8(\mathrm{~d})$.

\section{Hydraulic fracturing process in an isotropic medium with a perforated wellbore}

To understand influences of perforation on hydraulic fracturing, a series of $\mathrm{PFC}^{2 \mathrm{D}}$ models were established involving different perforation azimuths and perforation numbers. The numerical models have a width of $1,500 \mathrm{~mm}$ and a height of $1,500 \mathrm{~mm}$, which is assembled by means of about 26,000 particles with radii ranging from $4 \mathrm{~mm}$ to $6 \mathrm{~mm}$. As shown in Figure 2, a wellbore for fluid injection with a diameter of $140 \mathrm{~mm}$ is created at the centre of the model, and the depth and diameter of each perforation is about $80 \mathrm{~mm}$ and $20 \mathrm{~mm}$ respectively. The fluid injection rate is set to be $2.0 \times 10^{-5} \mathrm{~m}^{3} / \mathrm{s}$, and the viscosity of the fluid is set to be $1.0 \times 10^{-3} \mathrm{~Pa} \cdot \mathrm{s}$, while the micro-mechanical parameters and initial permeability of the rock models are listed in Table 1 of the sister paper (Zhou et al., 2016). The stress in $x$-direction $\left(S_{H}\right)$ is $30 \mathrm{MPa}$, while the stress in $y$ direction $\left(S_{V}\right)$ is $20 \mathrm{MPa}$.

\subsection{The influence of perforation azimuth}

Stress state around a wellbore will be complicated by the existence of perforations, which control the initial onset of hydraulic fractures (Wang 2015). To show the influences of perforation azimuth on fracture initiation and propagation, the authors consider four situations of included angles between a pair of perforation channels and the horizontal insitu stress in the modelling, i.e., $0^{\circ}, 30^{\circ}, 60^{\circ}$ and $90^{\circ}$. The modelling results are presented in Table 3 and Figure 10. 
Figure 8 Fracture distributions in laminated models of different inclination angles, with a fluid viscosity of $1.0 \times 10^{-3} \mathrm{~Pa} \cdot \mathrm{s}$ and a in-situ stress ratio of $S_{H} / S_{V}=30 \mathrm{MPa} / 20 \mathrm{MPa}$, (a) $2.0 \times 10^{-5} \mathrm{~m}^{3} / \mathrm{s}$ (b) $5.0 \times 10^{-5} \mathrm{~m}^{3} / \mathrm{s}$ (c) $1.0 \times 10^{-4} \mathrm{~m}^{3} / \mathrm{s}$ (d) $5.0 \times 10^{-4} \mathrm{~m}^{3} / \mathrm{s}$ (see online version for colours)
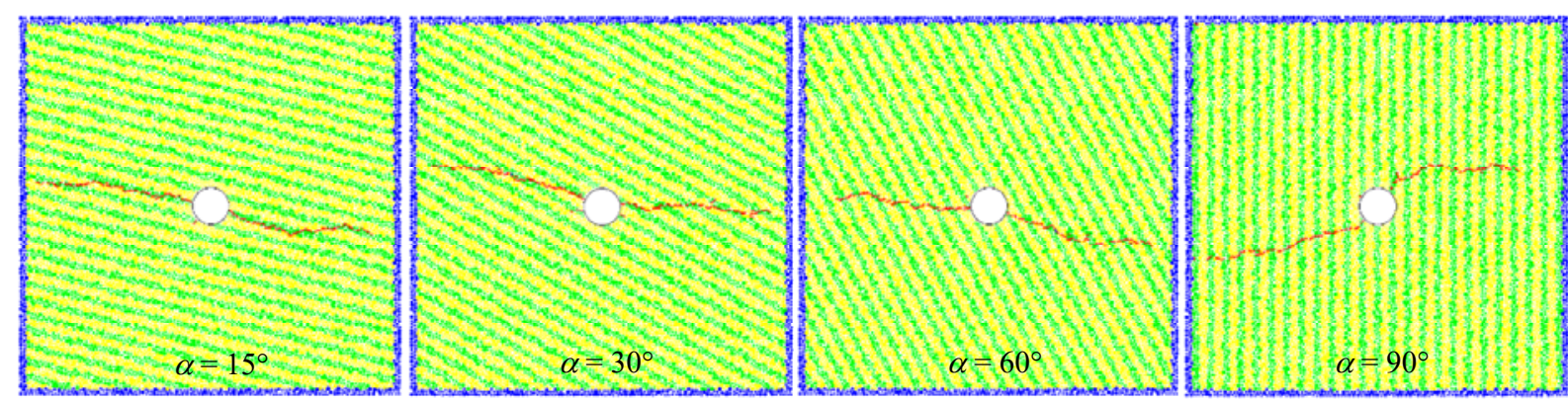

(a)
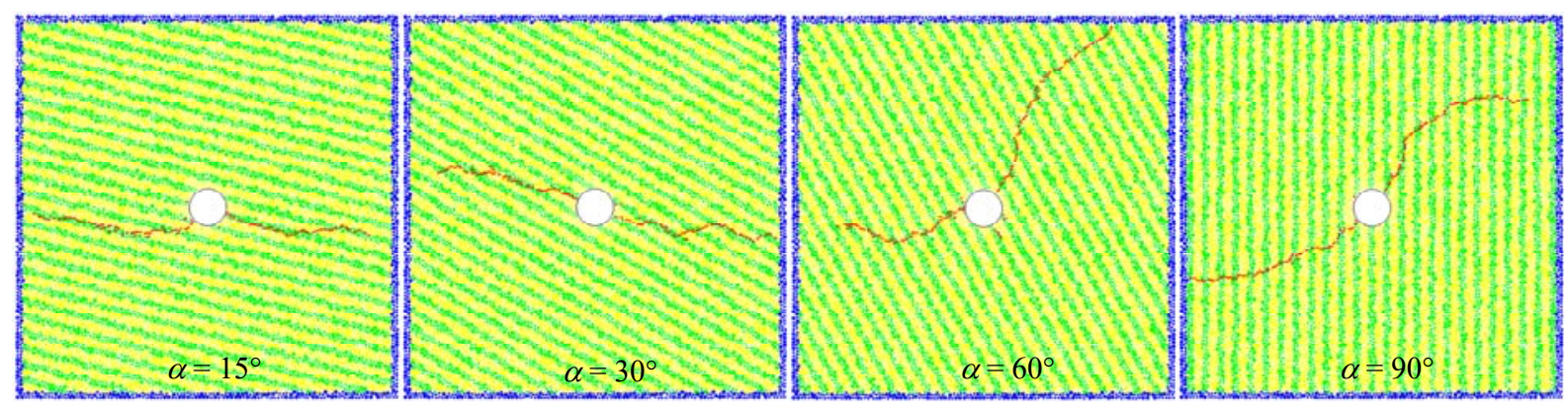

(b)
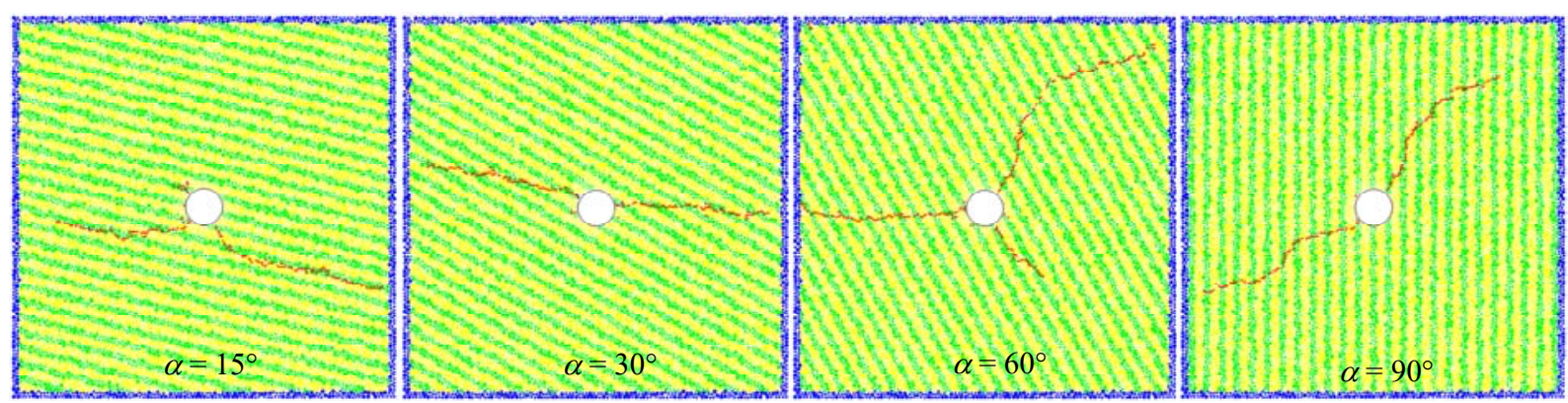

(c)
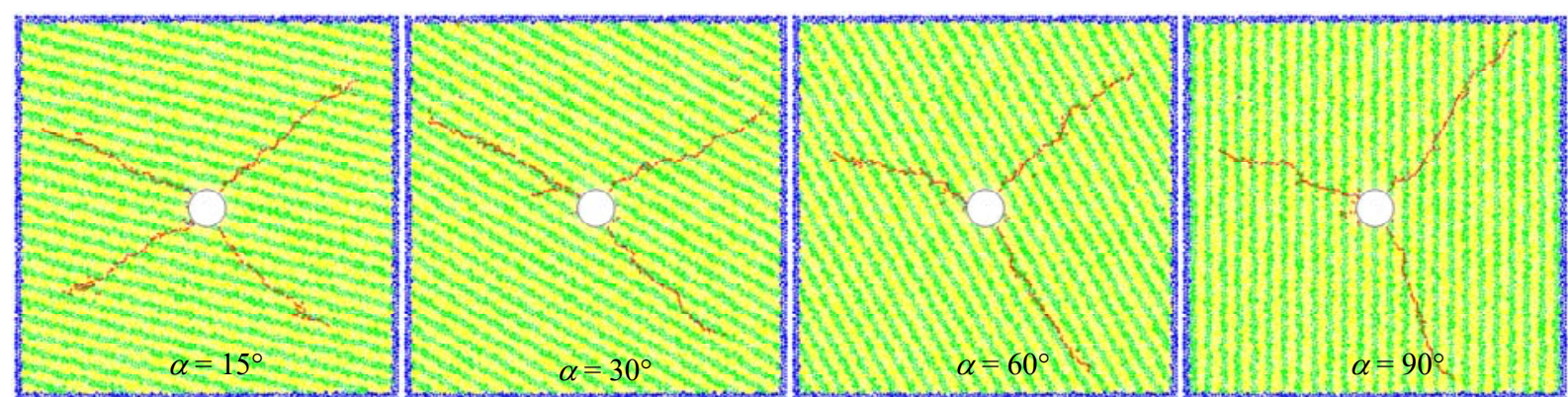

(d) 
Table 3 Modelling results of hydraulic fracturing around a perforated wellbore in an isotropic medium with an in-situ stress ratio of 1.5 $\left(S_{H} / S_{V}=30 \mathrm{MPa} / 20 \mathrm{MPa}\right)$ and a fluid viscosity of $1.0 \times 10^{-3} \mathrm{~Pa} \cdot \mathrm{s}$

\begin{tabular}{|c|c|c|c|c|c|c|c|}
\hline $\begin{array}{l}\text { Case } \\
\text { number }\end{array}$ & $\begin{array}{c}\text { Injection } \\
\text { rate } \\
\left(\mathrm{m}^{3} / \mathrm{s}\right)\end{array}$ & $\begin{array}{l}\text { Number of } \\
\text { perforation } \\
\text { channels }\end{array}$ & $\begin{array}{c}\text { Perforation } \\
\text { azimuth } \\
\alpha\end{array}$ & $\begin{array}{c}\text { Breakdown } \\
\text { pressure } \\
(\mathrm{MPa})\end{array}$ & $\begin{array}{l}\text { Number of } \\
\text { macroscopi } \\
\text { c fractures }\end{array}$ & $\begin{array}{l}\text { Fracture } \\
\text { initiation } \\
\text { location } \theta\end{array}$ & $\begin{array}{l}\text { Fracture number and description of } \\
\text { fracture propagation direction }\end{array}$ \\
\hline 1 & $2.0 \times 10^{-5}$ & 2 & $0^{\circ}$ & 48.0 & 2 & $0^{\circ}, 180^{\circ}$ & 1, 2. sub-horizontal \\
\hline 2 & & 2 & $30^{\circ}$ & 48.6 & 2 & $150^{\circ}, 330^{\circ}$ & 1. close to radial; 2 . sub-horizontal \\
\hline 3 & & 2 & $60^{\circ}$ & 54.0 & 2 & $120^{\circ}, 300^{\circ}$ & $\begin{array}{l}\text { 1, 2. a curved transition to } \\
\text { sub-horizontal }\end{array}$ \\
\hline 4 & & 2 & $90^{\circ}$ & 59.3 & 2 & $90^{\circ}, 270^{\circ}$ & 1. vertical; 2. sub-vertical \\
\hline 5 & $5.0 \times 10^{-4}$ & 2 & $60^{\circ}$ & 63.0 & 2 & $120^{\circ}, 300^{\circ}$ & $\begin{array}{l}\text { 1. turning to horizontal } \\
\text { 2. a curved transition to sub-horizontal }\end{array}$ \\
\hline 6 & & 4 & $45^{\circ}, 135^{\circ}$ & 64.4 & 3 & $\begin{array}{l}45^{\circ}, 135^{\circ} \\
225^{\circ}\end{array}$ & $\begin{array}{l}\text { 1. a curved transition to sub-horizontal } \\
2,3 \text {. radial }\end{array}$ \\
\hline 7 & & 6 & $\begin{array}{c}30^{\circ}, 90^{\circ} \\
150^{\circ}\end{array}$ & 61.1 & 2 & $30^{\circ}, 210^{\circ}$ & $\begin{array}{l}\text { 1, 2. fracture initiation and then turning } \\
\text { to sub-horizontal }\end{array}$ \\
\hline
\end{tabular}

Figure 9 Relative breakdown pressures for hydraulic fracturing around a wellbore in an anisotropic medium under different fluid injection rates (FIR) and dip angles of bedding plane, with a fluid viscosity of $1.0 \times 10^{-3} \mathrm{~Pa} \cdot \mathrm{s}$ and an in-situ stress ratio of $S_{H} / S_{V}=30 \mathrm{MPa} / 20 \mathrm{MPa}$ (see online version for colours)

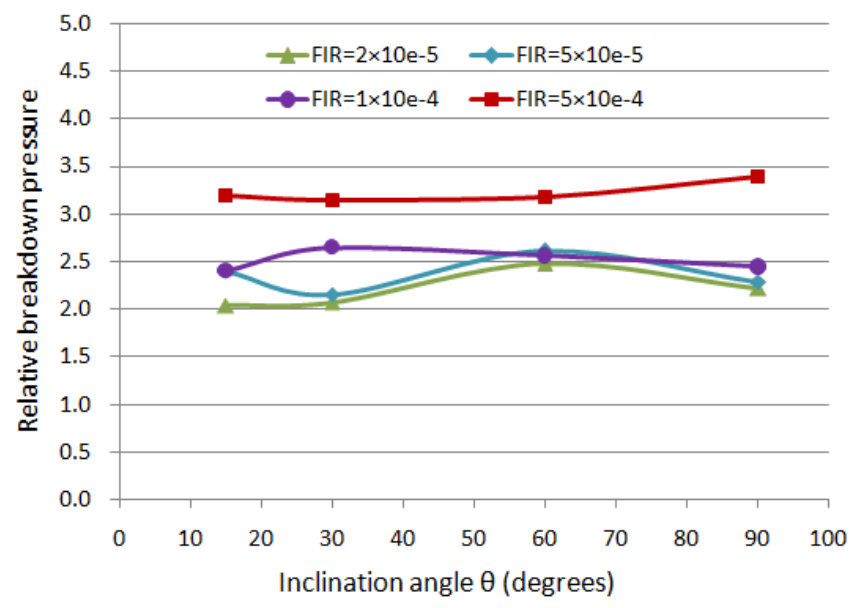

Seen from Figure 10, two fractures initiated respectively at the bottoms of two perforation channels in each case, where maximum tensile stress concentration often occurred due to fluid pressure around the perforated wellbore. The breakdown pressures increase as the perforation azimuth $(\alpha)$ increases, with a maximum difference of $24 \%$ between two cases. The PFP is horizontal due to in-situ stress ratio of 1.5 , and this effect was clearly shown in three situations of perforation azimuths $0^{\circ}, 30^{\circ}$ and $60^{\circ}$. When the perforations were horizontally placed at the right and left sides of the wellbore (i.e., $\alpha=0^{\circ}$ ), the two fractures propagated along the direction of horizontal in-situ stress from the beginning [Figure 10(a)]. Seen from situations $\alpha=30^{\circ}$ and $\alpha=60^{\circ}$ in Figures 10(b) and $10(\mathrm{c})$, the fractures will reorient themselves to propagate along the horizontal in-situ stress, with longer transferring distance in case of higher perforation azimuth. When $\alpha=90^{\circ}$, two fractures will propagate approximately along the vertical in-situ stress, without clear effects of in-situ stress ratio.

\subsection{The influence of perforation number}

The number of perforation channels is a key factor for developing complex fractures networks and gaining a higher stimulation volume during the design and implementation of hydraulic fracturing stimulation treatment. It is necessary to understand the mechanism about the influence of perforation number on hydraulic fracture propagation because few studies were reported in the literature. To understand effects of the perforation number, three models were respectively established for one pair, two pairs and three pairs of perforations around a horizontal wellbore in an isotropic medium. The fluid viscosity, fluid injection rate and in-situ stress ratio are kept to be constant ones, i.e., $1.0 \times 10^{-3} \mathrm{~Pa} \cdot \mathrm{s}, 5.0 \times 10^{-4} \mathrm{~m}^{3} / \mathrm{s}$ and $S_{H} / S_{V}=30 \mathrm{MPa} /$ $20 \mathrm{MPa}$. The modelling results are presented in Figure 11.

As shown in Figures 11(a), 11(b) and 11(c), three hydraulic fractures were induced in the model with two pairs of perforation channels, and only two fractures occurred in the other two models. This indicated that more perforations are not surely helpful for improving the fracturing stimulation efficiency, and the perforation number should be also optimised for effective fracturing stimulation. For the model with three pairs of perforations in Figure 11(c), the breakdown pressure is lowest because fractures firstly initiated at the ends of one pair of perforations having an included angle of $30^{\circ}$ with the maximum horizontal in-situ stress, and then reorient themselves to the preferred propagation direction. For the model in Figure 11(a), the perforations have an intersection angle of $45^{\circ}$ deviating from the preferred direction, so its breakdown pressure was bigger than that in Figure 11(c). For the model with two pairs of perforations in Figure 11(b), its breakdown pressure is maximum one due to initiation of three fractures. Influenced by in-situ stress ratio $1.5\left(S_{H} / S_{V}=30 \mathrm{MPa} / 20 \mathrm{MPa}\right)$ in the three models, all fractures will reorient their propagation to the horizontal in-situ stress after their initiations. 
Figure 10 Wellbore pressure histories and fracture patterns in numerical models under injection rate $2.0 \times 10^{-5} \mathrm{~m}^{3} / \mathrm{s}$, and fluid viscosity $1.0 \times 10^{-3} \mathrm{~Pa} \cdot \mathrm{s}$ and in-situ stress ratio $S_{H} / S_{V}=30 \mathrm{MPa} / 20 \mathrm{MPa}$, with different perforation azimuths, (a) $\alpha=0^{\circ}$ (b) $\alpha=30^{\circ}$ (c) $\alpha=60^{\circ}$ (d) $\alpha=90^{\circ}$ (see online version for colours)

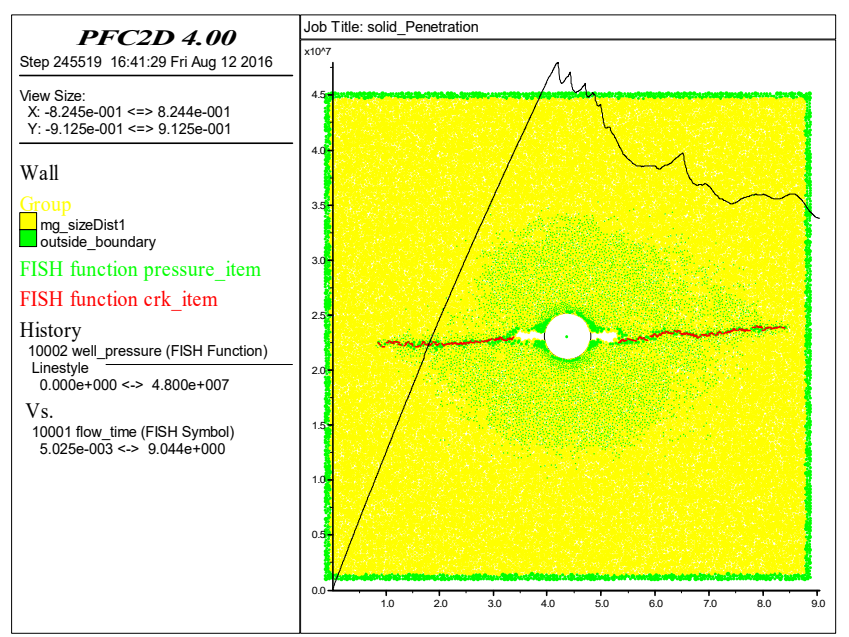

(a)

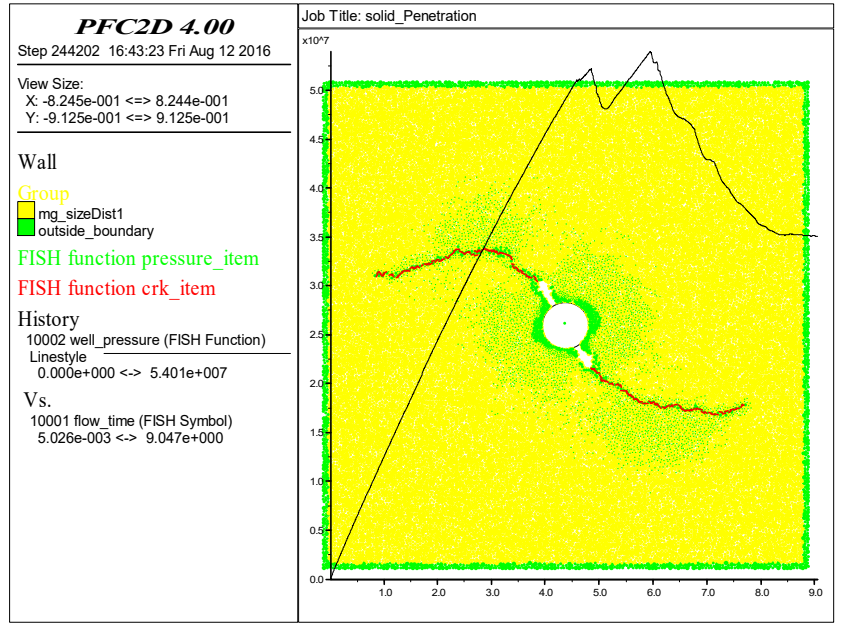

(c)

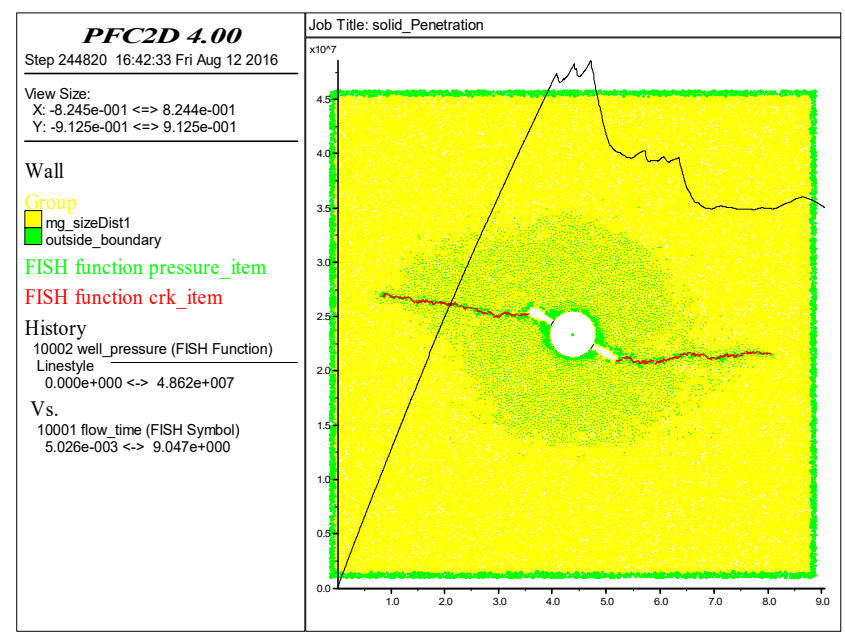

(b)

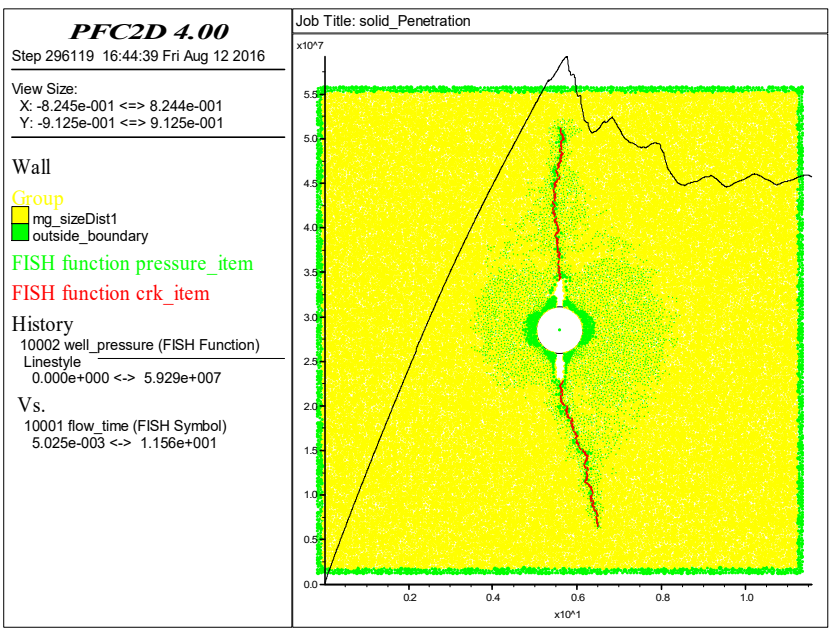

(d)

Figure 11 Fracture patterns in models with different pairs of perforations, (a) one pair of perforations (b) two pair of perforations (c) three pairs of perforations (see online version for colours)

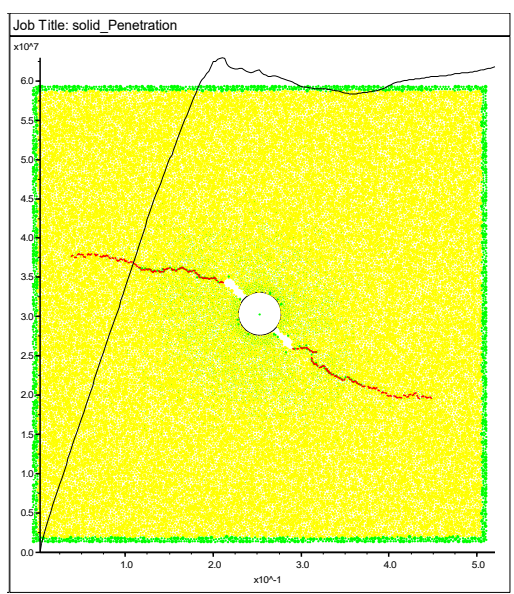

(a)

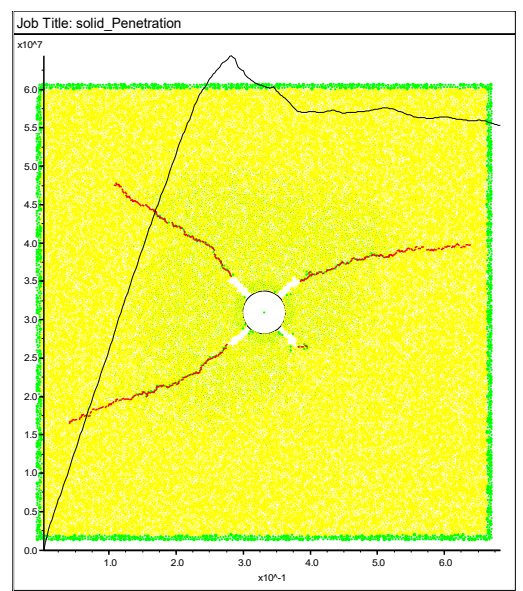

(b)

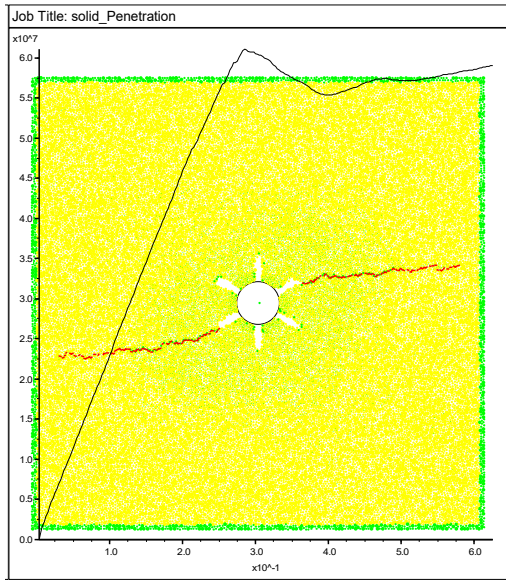

(c) 


\section{Conclusions}

Using a modified fluid-mechanically coupled $\mathrm{PFC}^{2 \mathrm{D}}$ model, the authors analysed hydraulic fracturing process for three groups of situations, i.e., isotropic rock mass with a wellbore, laminated reservoir rock with a wellbore, and perforated wellbore in isotropic medium. A series of simulations were performed to investigate the influence of in-situ stress ratio, fluid injection rate, layers' inclination angles, azimuth and number of perforation channels on the geometries of hydraulic fractures, respectively. In addition to good agreement with previous studies, and the main results are summarised as follows.

For an isotropic medium with a circular wellbore, the authors analysed the influences of in-situ stress ratios and fluid injection rates on hydraulic fracturing network. In-situ stress ratio plays an important role in fracture initiation and propagation. When the ratio is larger (i.e., larger difference in two directions of confining stresses), two hydraulic fractures will be macroscopically induced at maximum tensile stress concentrations, and they will often extend along the direction of the maximum principal stress or approach to this preferred path. Under same fluid viscosity and injection ratio, larger in-situ stress ratio will induce earlier fracture initiation, smaller breakdown pressure and faster fracture propagation. When the in-situ stress ratio is smaller (i.e., smaller difference in two directions of confining stresses), influences of fluid injection rate will increase. Smaller in-situ stress ratio or faster fluid injection rate is helpful for creating complex shapes and more numbers of hydraulic fractures, but higher breakdown pressure and longer injection time are needed for better reservoir stimulation efficiency.

When reservoir anisotropy is modelled by means of laminated rock, the authors found that fracture initiation and propagation will be influenced simultaneously by effects of weak layers, in-situ stress ratios and injection rates. For the laminated rock model, weak layers exposed along the wellbore are favourable for fracture initiation and propagation, especially in conditions of smaller in-situ stress ratios or lower fluid injection rates. When initial cracking direction is same as or similar to the layers' inclination, the breakdown pressures are tens percent lower than other cases of fracture propagation crossing layers. A series of modelling cases indicate that initiation and propagation of hydraulic fractures will be controlled by both in-situ stress ratios and anisotropic properties of the laminated rock. As in-situ stress ratios increase, the effects of weak layer will decrease and the fluctuation of relative breakdown pressure will also become smaller. As the injection rate increases, some initial cracks may occur in the strong layers of laminated rock, or cross the layers with bigger intersection angles, and more potential fractures may develop to be macroscopic ones. When the injection rate reaches a highest level, relative breakdown pressures will greatly increase with effects of weak layers and in-situ stress ratio becoming relatively weaker and weaker.

For an isotropic medium with a perforated wellbore, hydraulic fractures initiate easily at the bottoms of perforation channels, propagate generally along or approaching to the direction of maximum principal stress. The modelling results indicate that more perforations are not surely helpful for improving the reservoir stimulation efficiency, and the perforation number should be also optimised for effective fracturing stimulation. When in-situ stress ratio is bigger, all fractures will reorient their propagation to the horizontal in-situ stress after their initiations.

In the present paper, a modified 2-D particle flow code was successfully applied in hydraulic fracturing modelling in different situations of in-situ stress ratios, fluid injection rates, layers' inclinations and perforation parameters. The case studies demonstrate that the bonded particle method is a useful and strong tool for understanding hydraulic fracturing behaviour of reservoir rocks, and more simulation work on the naturally fractured reservoirs should be conducted by means of the modified $\mathrm{PFC}^{2 \mathrm{D}}$ model in the future.

\section{Acknowledgements}

This research is supported by funding from the National Natural Science Foundation of China (Grants 41572312, 41502307, 41272353) and the Strategic Priority Research Program of the Chinese Academy of Sciences (Grants XDB10030104). The authors thank Dr. Hazzard provided his original code for hydraulic fracturing modelling.

\section{References}

Al-Busaidi, A., Hazzard, J.F. and Young, RP. (2005) 'Distinct element modeling of hydraulically fractured Lac du Bonnet granite', Journal of Geophysical Research: Solid Earth, Vol. 110, No. B6, pp.1-14.

Alekseenko, O.P., Potapenko, D.I., Cherny, S.G., Esipov, D.V. and Kuranakov, D.S. (2012) '3-D modeling of fracture initiation from perforated non-cemented wellbore', in Proceedings of the SPE Hydraulic Fracturing Technology Conference, Woodlands, Texas, USA, 6-8 February.

Choi, S.O. (2012) 'Interpretation of shut-in pressure in hydrofracturing pressure-time records using numerical modeling', International Journal of Rock Mechanics and Mining Sciences, Vol. 50, pp.29-37.

De Laguna, W., Tamura, T., Weeren, H.O. et al. (1968) Engineering Development of Hydraulic Fracturing as a Method for Permanent Disposal of Radioactive Wastes, Oak Ridge National Lab., Tenn.

Fairhurst, C. (2003) 'Stress estimation in rock: a brief history and review', International Journal of Rock Mechanics and Mining Sciences, Vol. 40, No. 7, pp.957-973.

Fu, P., Johnson, S.M. and Carrigan, C.R. (2013) 'An explicitly coupled hydro-geomechanical model for simulating hydraulic fracturing in arbitrary discrete fracture networks', International Journal for Numerical and Analytical Methods in Geomechanics, Vol. 37, No. 14, pp.2278-2300.

Gautam, R. (2004) Anisotropy in Deformations and Hydraulic Properties of ColoradoShale, University of Calgary, Calgary, Civil Engineering. 
Geertsma, J. and De Klerk, F. (1969) 'A rapid method of predicting width and extent of hydraulically induced fractures', Journal of Petroleum Technology, Vol. 21, pp.1571-1581.

Haimson, B.C. and Cornet, F.H. (2003) 'ISRM suggested methods for rock stress estimation - part 3: hydraulic fracturing (HF) and/or hydraulic testing of pre-existing fractures (HTPF)', International Journal of Rock Mechanics and Mining Sciences, Vol. 40, No. 7, pp.1011-1020.

Hamidi, F. and Mortazavi, A. (2012) 'Three dimensional modeling of hydraulic fracturing process in oil reservoirs', 46th US Rock Mechanics/Geomechanics Symposium, American Rock Mechanics Association.

Hamidi, F. and Mortazavi, A. (2014) 'A new three dimensional approach to numerically model hydraulic fracturing process', Journal of Petroleum Science and Engineering, Vol. 124, pp.451-467.

Hazzard, J.F., Young, R.P. and Oates, S.J. (2002) 'Numerical modeling of seismicity induced by fluid injection in a fractured reservoir', Mining and Tunnel Innovation and Opportunity, Proceedings of the 5th North American Rock Mechanics Symposium, Toronto, Canada, pp.1023-1030.

Itasca Consulting Group Inc. (2008) PFC2D - Particle Flow Code in 2 Dimensions, Version 4.0, Minneapolis.

Khristianovic, S. and Zheltov, Y. (1955) 'Formation of vertical fractures by means of highly viscous fluids', in Proceedings of the 4th World Petroleum Congress, Rome, Italy, 6-15 June, Vol. 2, pp.579-586.

King, G.E. (2010) 'Thirty years of gas shale fracturing: what have we learned?', in Proceedings of the SPE Annual Technical Conference and Exhibition, Florence, Italy, 19-22 September.

Li, Y., Liu, G., Li, J., Yu, L., Zhang, T. and Lu, J. (2015) 'Improving fracture initiation predictions of a horizontal wellbore in laminated anisotropy shales', Journal of Natural Gas Science and Engineering, Vol. 24, pp.390-399.

Nordgren, R.P. (1972) 'Propagation of a vertical hydraulic fracture', Society of Petroleum Engineers Journal, Vol. 12, No. 4, pp.306-314.
Perkins, T.K. and Kern, L.R. (1961) 'Widths of hydraulic fractures', Journal of Petroleum Technology, Vol. 13, No. 9, pp.937-949.

Shimizu, H., Murata, S. and Ishida, T. (2011) 'The distinct element analysis for hydraulic fracturing in hard rock considering fluid viscosity and particle size distribution', International Journal of Rock Mechanics and Mining Sciences, Vol. 48, No. 5, pp.712-727.

Wang, H. (2015) 'Numerical modeling of non-planar hydraulic fracture propagation in brittle and ductile rocks using XFEM with cohesive zone method', Journal of Petroleum Science and Engineering, Vol. 135, pp.127-140.

Yokoyama, T., Sano, O., Hirata, A. et al. (2014) 'Development of borehole-jack fracturing technique for in situ stress measurement', International Journal of Rock Mechanics and Mining Sciences, Vol. 67, pp.9-19.

Zangeneh, N., Eberhardt, E. and Bustin, R.M. (2015) 'Investigation of the influence of natural fractures and in situ stress on hydraulic fracture propagation using a distinctelement approach', Canadian Geotechnical Journal, Vol. 52, No. 7, pp.926-946.

Zhao, X. and Young, R.P. (2011) 'Numerical modeling of seismicity induced by fluid injection in naturally fractured reservoirs', Geophysics, Vol. 76, No. 6, pp.WC167-WC180.

Zhou, J., Zhang, L. and Han, Z. (2016) 'Hydraulic fracturing process by using a modified two-dimensional particle flow code - method and validation', Progress in Computational Fluid Dynamics (submitted).

Zimmermann, G., Moeck, I. and Blöcher, G. (2010) 'Cyclic waterfrac stimulation to develop an enhanced geothermal system (EGS) - conceptual design and experimental results', Geothermics, Vol. 39, No. 1, pp.59-69.

Zimmermann, G., Tischner, T., Legarth, B. et al. (2009) 'Pressuredependent production efficiency of an enhanced geothermal system (EGS): stimulation results and implications for hydraulic fracture treatments', Rock Physics and Natural Hazards, Birkhäuser Basel, pp.1089-1106. 